\title{
Road induced edge effects on a forest bird community in tropical Asia
}

\author{
Daphawan Khamcha ${ }^{1 *}$ (D) Richard T. Corlett ${ }^{2}$, Larkin A. Powell ${ }^{3}$, Tommaso Savini ${ }^{1}$, Antony J. Lynam ${ }^{4}$ \\ and George A. Gale ${ }^{1}$
}

\begin{abstract}
Background: Edge effects cause changes in bird community richness, abundance, and/or distribution within a landscape, but the avian guilds most influenced can vary among regions. Although Southeast Asia has the highest rates of deforestation and projected species loss, and is currently undergoing an explosive growth in road infrastructure, there have been few studies of the effects of forest edges on avian communities in this region.

Methods: We examined avian community structure in a dry evergreen forest in northeastern Thailand adjacent to a five-lane highway. We evaluated the richness and abundance of birds in 11 guilds at 24 survey points on three parallel transects perpendicular to the edge. At each point, 10-min surveys were conducted during February-August 2014 and March-August 2015. Vegetation measurements were conducted at 16 of the bird survey points and ambient noise was measured at all 24 survey points.

Results: We found a strongly negative response to the forest edge for bark-gleaning, sallying, terrestrial, and understory insectivores and a weakly negative response for arboreal frugivore-insectivores, foliage gleaning insectivores, and raptors. Densities of trees and the percentage canopy cover were higher in the interior, and the ambient noise was lower. In contrast, arboreal nectarivore-insectivores responded positively to the forest edge, where there was a higher vegetation cover in the ground layer, a lower tree density, and a higher level of ambient noise.
\end{abstract}

Conclusion: Planners should avoid road development in forests of high conservation value to reduce impacts on biodiversity. Where avoidance is impossible, a number of potential mitigation methods are available, but more detailed assessments of these are needed before they are applied in this region.

Keywords: Road edge, Avian guilds, Dry evergreen forest, Thailand

\section{Background}

Forest habitat conversion and degradation, which was already widespread globally by the mid-18th century, has continued to increase, especially in the tropics over the past half century (Haddad et al. 2015). The resulting fragmentation means that much of the remaining forest is now potentially subject to edge effects (Barber et al. 2014; Haddad et al. 2015). Infrastructure development, especially roads and reservoirs, is projected to continue to increase in the coming decades, reducing the

\footnotetext{
*Correspondence: daphawan@gmail.com

${ }^{1}$ Conservation Ecology Program, School of Bioresources and Technology, King Mongkut's University of Technology Thonburi, Bangkok, Thailand Full list of author information is available at the end of the article
}

conservation value of intact forest landscapes (Potapov et al. 2017) and bringing an increasing proportion of the remaining forest closer to edges (Laurance et al. 2015).

Edges can act as barriers for birds and can affect genetic diversity, species distributions, species abundances, and nest survival, which can lead to local species extinctions (Newmark and Stanley 2011; Mammides et al. 2015). Edges alter the physical environment of forest habitats via increased sunlight, temperature extremes, and wind exposure, and reduced humidity, directly influencing vegetation structure and food availability, which may, in turn, cause changes in the avian community. Such changes may render edge habitats unsuitable for some bird species (Murcia 1995). Roadside edges not only change the physical environment, but also lead 
to increased traffic noise and potential road mortality that may directly impact populations, distributions, and behaviours of some bird species (Halfwerk et al. 2011; Jack et al. 2015).

Edge preference or avoidance by birds probably depends on multiple traits, including biogeographic origin, trophic guild, body size, degree of habitat specialization, reproductive rates (Ewers and Didham 2006; Barbaro and van Halder 2009; Vetter et al. 2011). Avian guilds respond to edge effects differently. Species that require forest interior for foraging or breeding, as well as those with specific or specialized diets or foraging behaviours, may avoid edges because the altered vegetation structure or microclimate, higher anthropogenic noise levels, and/or higher predation pressure or brood parasitism, may affect their foraging habitats (Newton 1994; Menke et al. 2012).

The responses of avian communities to edge effects vary from site to site in tropical forest habitats (Restrepo and Gomez 1998; Watson et al. 2004; Vetter et al. 2013). Certain guilds in tropical forests, particularly insectivores, ground foragers, and bark gleaners, often occur at lower densities close to edges (Lambert and Collar 2002; Mammides et al. 2015). In temperate forests, in contrast, insectivorous birds make greater use of edges because higher plant productivity leads to higher abundance of arthropod larva (Barber and Marquis 2011; Terraube et al. 2016). Edge habitats in tropical forests may also contain more food resources, but other mechanisms, such as altered vegetation structure and microclimates, and increased predation, may counter these positive effects (Flaspohler et al. 2001; Pollock et al. 2015). Indeed, several studies, from both tropical and temperate regions, have found that nectarivores and frugivores were commonly closer to edges (Dale et al. 2000; Laurance 2004; Lindell et al. 2007). This may reflect vegetation structure at the edge which supports higher food availability (i.e. fruit and nectar) compared with the interior (Bierregaard and Stouffer 1997; Restrepo et al. 1999). Utilization of edge habitats by some species appears to be a trade-off between the risks of predation and/or the unfavourable physical or biological conditions versus preferred foraging habitats.

Southeast Asia has the highest rate of forest loss in the tropics (Stibig et al. 2014; Wilcove et al. 2013) as result of industrial scale logging, the expansion of monoculture cash crops and, more recently, an explosion in infrastructure construction (Laurance et al. 2015; Sloan and Sayer 2015). Although there have been several studies of edge effects on avian communities, most have been conducted in temperate regions (Bennett 2017). Few studies have been conducted in the tropics, especially tropical Asia (Wong et al. 1998; Lambert and
Collar 2002; Lee et al. 2005; Moradi et al. 2009; Dayananda et al. 2016); most ecological and conservation studies in the tropics are conducted in continuous primary forest and forest interiors. In view of the high rate of forest loss and rapid increase in infrastructure development in Southeast Asia, however, a better understanding of how avian communities respond to forest edges and which mechanisms influence this response is needed to improve forest management and mitigate potentially adverse impacts from road construction. The aim of this study, therefore, was to investigate the effects of a roadside forest edge on avian community structure in a Southeast Asian tropical forest. Our specific objectives were to (1) determine how the forest edge affected the avian community and (2) identify the potential mechanisms that influence these edge effects. Based on previous studies in tropical regions (Watson et al. 2004; Mammides et al. 2015), we predicted that (1) edge effects would influence each avian guild differently, and (2) richness and abundance of some avian guilds, particularly understory, sallying, terrestrial, and bark gleaning insectivores, would be higher in the forest interior than the forest edge because the interior is likely to provide more suitable habitats.

\section{Methods \\ Study area}

The study was conducted in the Sakaerat Environmental Research Station (SERS), which is part of the Phuluang Non-hunting Area, with a total forest area of $160 \mathrm{~km}^{2}$. SERS was declared a UNESCO Biosphere Reserve in 1977. It is located in northeastern Thailand $\left(14^{\circ} 30 \mathrm{~N}\right.$, $101^{\circ} 55^{\prime} \mathrm{E}$ ), with an elevation of $280-762 \mathrm{~m}$ asl. The average annual rainfall is approximately $1200 \mathrm{~mm}$, with the dry season (average rainfall $220 \mathrm{~mm}$ ) generally occurring from November to April and the wet season (average rainfall $920 \mathrm{~mm}$ ) from May to October. The average temperature is $27{ }^{\circ} \mathrm{C}$, ranging from 19 to $36^{\circ} \mathrm{C}$ over the year. SERS has a five-lane highway to the south, villages and agricultural areas to the east and west, and the northeast is connected to the Lam Phra Phloeng Dam. It includes two major forest types, dry evergreen forest covering $70 \%$ of the area and dry dipterocarp forest covering $20 \%$, with the rest consisting of small patches of bamboo, plantations, and grassland. The study focused on an area within dry evergreen forest ranging in elevation from 355 to $523 \mathrm{~m}$ asl within a kilometre of the forest edge (Fig. 1). This edge is "hard", in the sense that the forest ends abruptly at a five-lane highway (Route 304). The road has been in place for over 60 years but there has been recent widening along part of its length with consequent loss of native vegetation on both sides. 

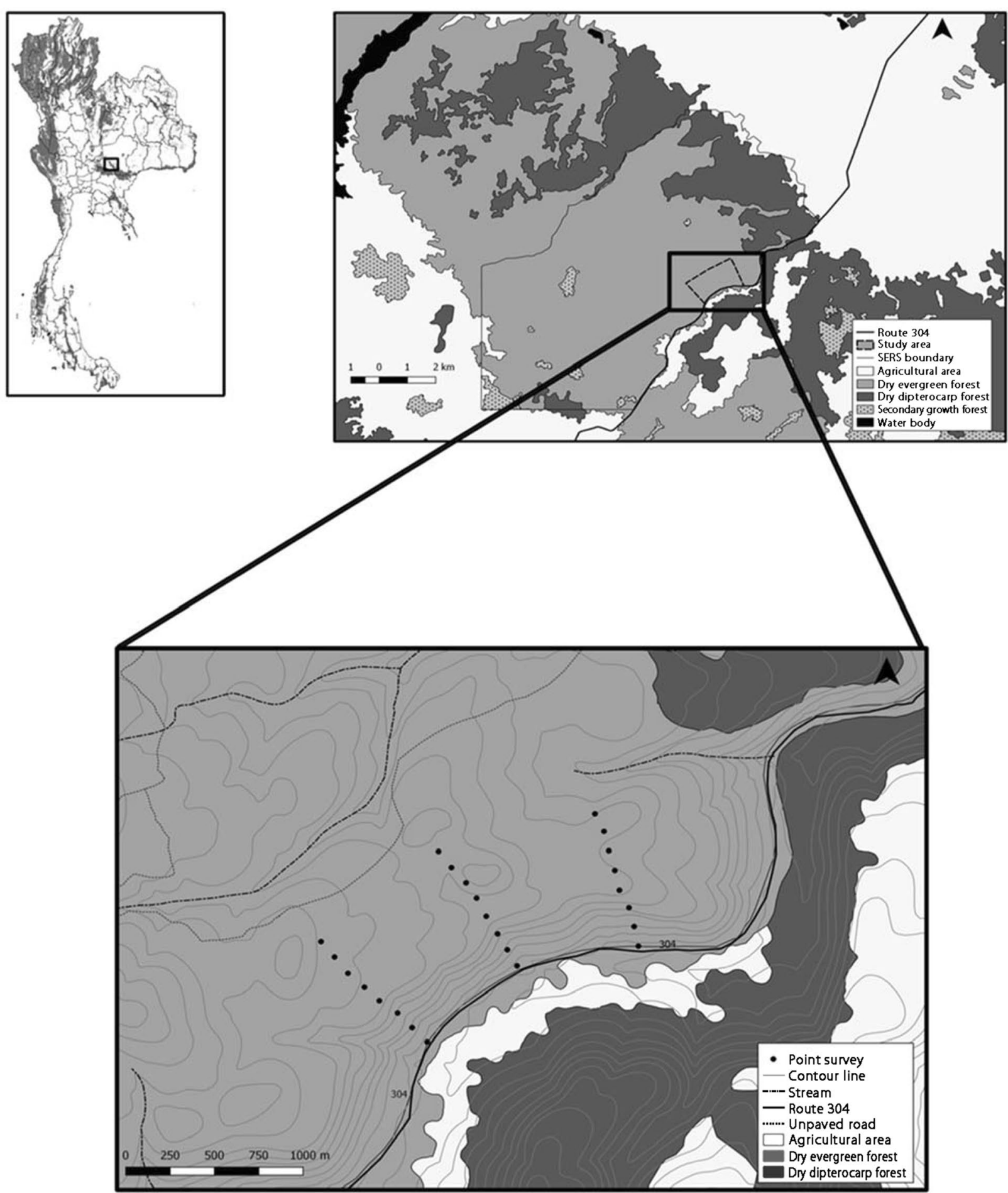

Fig. 1 The location of the study area at the Sakaerat Environmental Research Station, Thailand in 2014-2015. Insets show the area's location in Thailand (upper left), the boundary of study area and landscape context (upper right) and details of the study area including the road edge (Route 304) and survey points (dots) (below) 


\section{Bird surveys}

We conducted bird surveys using point-counts during the breeding season February-August 2014 and MarchAugust 2015. Our bird sampling units consisted of survey points (16 points during 2014, 24 points in 2015, 24 in total) set up along parallel transects (eight points/ transect). Transects were $700 \mathrm{~m}$ apart. The total area sampled was approximately 140 ha of dry evergreen forest and was adjacent to the highway (Fig. 1). The points were arranged to sample a gradient of distances 0,120 , $240,360,480,600,720$, and $840 \mathrm{~m}$ from the edge; thus, in total our design resulted in three points at each distance from the edge. Survey points were $>700 \mathrm{~m}$ from other forest types (Fig. 1). Each point was surveyed for 10 min during each survey (Gale et al. 2009). To reduce the bias of time of the day, the starting point was reversed each month. From February to May 2014 we conducted surveys at 8 points (one point at each distance from the edge) twice per month, and from June to August 2014 we surveyed 16 points (two points at each distance) once per month. During 2015 from March to August we conducted monthly surveys at 24 points (three points at each distance) and to increase the number of surveys in July and August 2015 we repeated the surveys (a day after completing the initial 24 points) on eight of these points (one point at each distance), with the aim of accounting for every species present in our study area regardless of its detectability (Sliwinski et al. 2016). The detections were recorded as either seen or heard or both. Birds in flight were not counted. Points were surveyed in the early morning, starting at approximately 06:00 a.m. (sunrise) and finishing before 09:00 a.m., as this time has the highest singing rates (Gale et al. 2009). All point-count surveys were conducted by one observer to minimize potential variance among observers (Ralph et al. 1993).

We classified birds into 11 guilds following Johns (1986) and Lambert and Collar (2002): arboreal frugivore-insectivore (AFI), arboreal nectarivore-insectivore (ANI), bark-gleaning insectivore (BGI), foliage-gleaning insectivore (FGI), granivore-insectivore (GI), raptor (R), sallying insectivore (SaI), terrestrial insectivore (TI), terrestrial insectivore-faunivore (TIV), terrestrial insectivore-frugivore (TIF), and understory insectivore (UI) (Additional file 1: Table S1).

\section{Vegetation measurements}

Vegetation structure is expected to change along a forest edge, which has the potential to be a mechanism to influence the composition of the bird community. To quantify vegetation structure, we measured the potentially influential vegetation variables; $10-\mathrm{m}$ radius circular plots were established at the 16 bird survey points which were surveyed in 2014. Within each plot we counted the number of stems in three height classes $(0.5-3 \mathrm{~m},>3-5 \mathrm{~m}$ and $>5 \mathrm{~m}$ ) in order to estimate stem density (stems/ha) and measured the DBH (diameter breast height) of all trees with $\mathrm{DBH}>5 \mathrm{~cm}$ in order to estimate the basal area $\left(\mathrm{m}^{2} / \mathrm{ha}\right)$. The percentage vegetation cover was estimated for five plant height classes: $<0.5 \mathrm{~m},>0.5-3 \mathrm{~m},>3-5 \mathrm{~m}$, > 5-10 $\mathrm{m}$ and $>10 \mathrm{~m}$.

\section{Traffic noise}

Ambient noise is expected to be high close to the road edge, which could affect the bird community close to the road edge. To investigate the potential effects of traffic noise on avian guilds, ambient noise measurements were conducted during bird surveys at the 24 bird survey points during March-August 2015. At each of the bird survey points we measured ambient noise in decibels $(\mathrm{dB})$ for 10 min using the application Sound Meter version 1.6.1 on a smartphone (Lenovo A680) held $1.2 \mathrm{~m}$ above the ground pointed towards the road. We recorded the average, minimum and maximum ambient noise for each sample period.

\section{Data analysis}

To assess the effect of the forest edge on the richness (number of species observed) and abundance (counts) of the avian community sampled from the 24 survey points, we categorized our avian data into guilds and constructed generalized linear mixed models (GLMM) in $\mathrm{R}$ using package lme4 (Bolker et al. 2011). GLMM provides a flexible approach for analysing data with a variety of sampling units with uneven and small sample sizes and repeated samples that allows for random effects. We modelled abundance and richness using a Poisson distribution. Our models included fixed effects of vegetation (vegetation density, stem density of vegetation with heights between $0.5-3 \mathrm{~m}, 3-5 \mathrm{~m}, 5-10 \mathrm{~m}$, and stem density of trees with $\mathrm{DBH}>5 \mathrm{~cm}$, vegetation cover-percentage cover of vegetation at $<0.5 \mathrm{~m}, 0.5-3 \mathrm{~m}, 3-5 \mathrm{~m}$, 5-10 $\mathrm{m}$ and $>10 \mathrm{~m}$, and basal area), ambient noise, and distance from forest edge. Although we collected vegetation structure data for only 16 of the 24 bird survey points, our preliminary surveys and recent measurements of vegetation structure in the same study area found that the vegetation structure followed a consistent pattern along our interior-edge distance gradient ( $R$. Angkeaw, unpubl. data; W. Petersen, unpubl. data). For the data analysis we used averaged values to represent the vegetation at each of the 8 distances sampled from the road. We used avian guilds as a random effect to allow for different responses to the edge among guilds. We used maximum ambient noise in this analysis, as this is likely to have the most effect on the avian community 
relative to other noise measurements (Ware et al. 2015). We did not conduct ambient noise measurements in 2014, but a traffic survey by the Bureau of Highway Safety, Department of Highways, on Route 304 along our study area in 2014 (Department of Highway 2014) found a similar traffic volume to our study in 2015 (678 vs. 609 vehicles/h). Since traffic noise is determined by traffic volume (Arevalo and Newhard 2011), we used our 2015 data to represent the ambient noise in both years.

We excluded year and spatial variables (transect and elevation) from this analysis as we found no support for either of them affecting counts or richness. One variable of any pair that was highly correlated $(r>0.7)$ was removed from the analysis. We expected that ambient noise and vegetation variables would change with distance from the edge, so when these factors were correlated with distance, we regarded distance from edge as the best predictor of changes in species richness and abundance of avian guilds.

To evaluate the effect of the forest edge on each guild, we generated models with random slopes and intercepts. We generated AIC tables (R-package AICcmodelavg) for model selection based on AIC values. We used model averaging to estimate values of parameters if $\geq 1$ model was within two $\triangle \mathrm{AIC}$ of the top model. We considered the evidence of variable influence on species richness and abundance using $85 \%$ confidence intervals, which are considered more suitable for model selection and parameter-evaluation criteria than the narrower 95\% confidence intervals (Arnold 2010). We then created estimated regression lines and calculated estimated coefficients, standard errors, and confidence intervals for each guild from the top-ranked model to indicate the responses of each guild to the possible edge effects. The predicted response, $y$ (species richness or abundance), for each guild, $g$, to distance from forest edge, $X$, was calculated by holding the vegetation variable at its mean, $\bar{V}$, as shown by the following equation (Gelman and Hill 2007):

$$
y=\alpha_{f}+\alpha_{r}+\beta_{f i} \bar{V}+\beta_{f x} X+\beta_{f * x} X \bar{V}+\beta_{r g} X
$$

where $\alpha_{f}=$ intercept of the fixed effects, $f ; \alpha_{r}=$ intercept of the random effect, $r ; \beta_{f i}=$ coefficient for the fixed vegetation variable; $\beta_{f x}=$ coefficient for distance, $X$, from edge; $\beta_{f * x}=$ coefficient of interaction between vegetation and distance; and $\beta_{r g}=$ coefficient of the random effect for the guild of interest.

\section{Results}

\section{Bird species richness and abundance}

A total of 272 independent surveys were conducted during our two-year study. We recorded 2781 detections and identified 70 species of birds (Additional file 1: Table S1). Some species were observed for relatively short periods, such as migratory species; e.g. a group of warblers, cuckoos and the Siberian Blue Robin (Larvivora cyane). Most species $(69 \%)$ could be found at every distance from the edge into the interior, but some species were recorded at particular distances from the edge, including three species of woodpeckers, Orange-breasted Trogon (Harpactes oreskios), Oriental Pied Hornbill (Anthracoceros albirostris), and Thick-billed Green Pigeon (Treron curvirostra), which were found only in the interior. On the other hand, there were some species found only near the edge, such as prinias (Prinia sp.), Asian Koel (Eudynamys scolopacea), Scaly-breasted Munia (Lonchura punctulata), and Olive-backed Sunbird (Cinnyris jugularis). Total bird species richness and abundance (including both resident and migratory birds) both increased with distance from the edge, but this relationship was only marginally significant for abundance (richness: $R^{2}=0.95$, $p<0.001$; abundance: $R^{2}=0.69, p=0.056$ ) (Fig. 2).

\section{Vegetation structure}

Hopea ferrea (Dipterocarpaceae), Lagerstroemia duperreana (Lythraceae), and Shorea henryana (Dipterocarpaceae) were the dominant species in the canopy layer $(>30 \mathrm{~m})$. The dominant species in the understory layer $(<20 \mathrm{~m})$ were Hydnocarpus ilicifolia (Flacourtiaceae), Walsura trichostemon (Meliaceae), Memecylon ovatum (Melastomataceae), and Memecylon geddesianum (Melastomataceae). The total basal area for trees with $\mathrm{DBH}>5 \mathrm{~cm}$ was $28.18 \mathrm{~m}^{2} /$ ha. The stem density was 15,524 stems/ha for stems $0.5-3 \mathrm{~m}$ in height, 642 stems/ ha for stems $3-5 \mathrm{~m}$, and 1176 stems/ha for stems $>5 \mathrm{~m}$. The stem density for trees with $\mathrm{DBH}>5 \mathrm{~cm}$ was 1202 stems/ha. Estimated mean vegetation cover by height layers was $44 \%<0.5 \mathrm{~m} ; 72 \% 0.5-3 \mathrm{~m} ; 55 \% 3-5 \mathrm{~m}$; $63 \% 5-10 \mathrm{~m}$; and $81 \%>10 \mathrm{~m}$.

When we considered the vegetation structure from the forest edge into the interior, we found that the total basal area was larger further from the edge (Fig. 3). The stem density of trees was also higher at the interior. The stem density of saplings was higher at both edge and deeper interior areas, relative to intermediate distances (Fig. 3). The percentage cover of the vegetation from the ground to the middle layer was higher closer to the edge in contrast to the percentage cover of vegetation at the canopy layer which was higher further from the edge (Fig. 3).

\section{Traffic noise}

From March-August 2015 the mean ambient noise was $45 \mathrm{~dB}$ (range: $29-82 \mathrm{~dB}$ ). The mean maximum ambient noise within $100 \mathrm{~m}$ of the forest edge was $75 \mathrm{~dB}$ (range: 67-82 dB) and in the interior (at $800 \mathrm{~m}$ ) was $58 \mathrm{~dB}$ (range: $42-69 \mathrm{~dB}$ ) (Fig. 3). The mean traffic noise on low traffic days was $44 \mathrm{~dB}$ (range: $29-78 \mathrm{~dB}$ ) and 

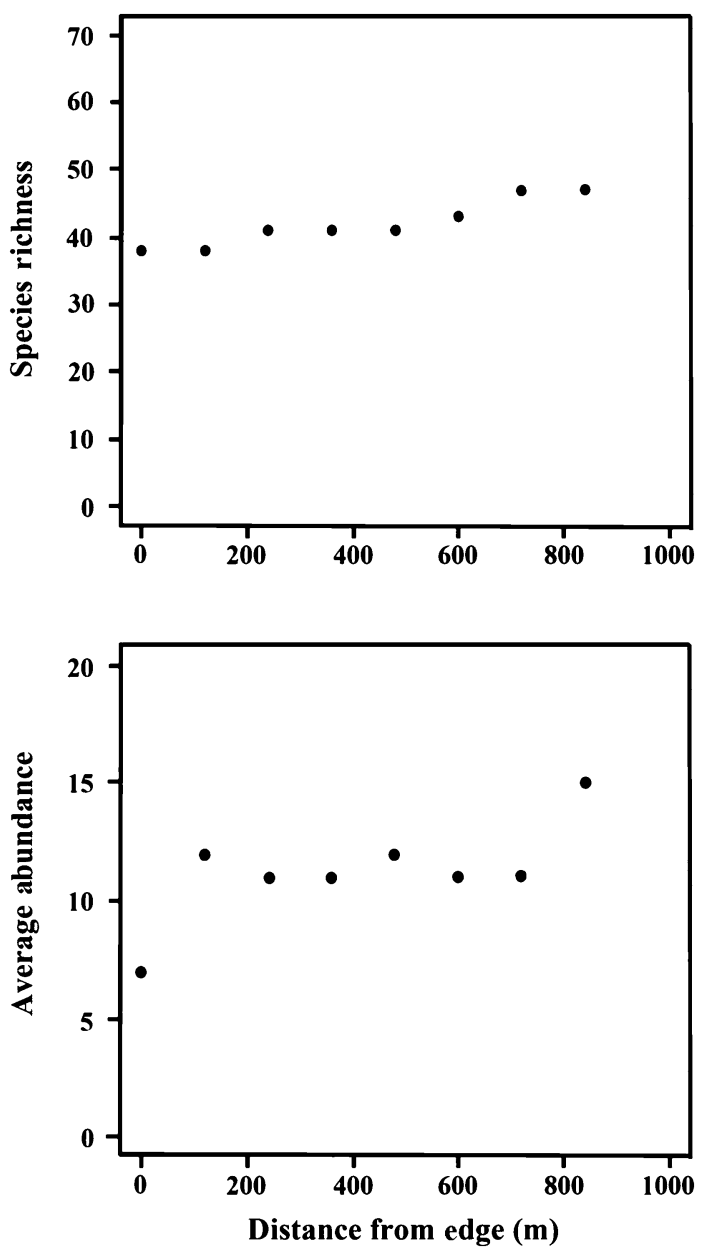

Fig. 2 Total species richness and average abundance of birds in relation to distance from the forest edge at the Sakaerat Environmental Research Station in 2014-2015

on high traffic days was $45 \mathrm{~dB}$ (range: $33-82 \mathrm{~dB}$ ). Total traffic volume on Route 304 was 553-700 vehicles/h and average traffic volume was 609 vehicles/h. Average traffic volume on the low traffic days was 564 vehicles/h (range: 553-582 vehicles/h) and average traffic volume on the high traffic days was 642 vehicles/h (range: 586700 vehicles/h). Ambient noise was significantly higher closer to the forest edge, especially within $100 \mathrm{~m}$ of the edge, and gradually decreased towards the interior $\left(R^{2}=0.90, p=0.002\right)$.

\section{Avian guild responses to forest edge}

We removed four variables that were correlated $(r>0.7)$ with distance from edge: basal area and the percentage coverage of vegetation at $>10 \mathrm{~m}$ height, which were positively correlated with distance from edge, and maximum ambient noise and percentage coverage of vegetation at 3-5 m height, which were negatively correlated with distance from edge. We retained distance from edge as a fixed effect to represent effects of these four variables (Fig. 3).

We generated 22 models for the effects of forest edge on richness and abundance of avian guilds. The topranked models for both species richness and abundance were interaction models that included two variables, distance from edge and stem density of saplings (i.e. stems of height $0.5-3 \mathrm{~m}$ ), while other models with strong support $(\triangle \mathrm{AICc}<2)$ also included the percentage cover of vegetation at $<0.5 \mathrm{~m}$ and $5-10 \mathrm{~m}$ (Table 1). Following model averaging, the variables with a significant positive influence on species richness were stem density of saplings $(\beta=0.33)$ and the interaction between distance from edge and the percentage cover at $<0.5 \mathrm{~m}(\beta=0.35)$, while the interaction between distance from edge and stem density of saplings $(\beta=-0.23)$ (Table 2 ) was significantly negatively associated with species richness. For abundance, stem density of saplings $(\beta=0.49)$ was significantly positively associated with abundance, while the interaction between distance from edge and stem density of saplings $(\beta=-0.29)$ and the percentage cover at $5-10 \mathrm{~m}(\beta=-0.32)$ had a significant negative influence (Table 2).

For guild-specific predictions, the models suggested that there was an effect of the distance from edge and vegetation structure on richness and abundance of avian guilds, and distance to edge also represented ambient noise and several characteristics of vegetation structure because of correlations (Fig. 3). However, each guild responded differently to the edge (Fig. 4). We found some evidence to support negative effects of forest edge on richness of barkgleaning, sallying, terrestrial, and understory insectivores and we also found some evidence of negative edge effects on arboreal frugivore-insectivores (Table 3; Fig. 4a). The richness of these guilds were higher at greater distances from the edge, where the density of saplings, basal area, and percentage cover of higher vegetation layers were higher, but percentage cover of lower layers $(0.5-5 \mathrm{~m})$ and ambient noise were lower (Fig. 3). Edge effects seemed to have positive effects on richness of arboreal nectarivore-insectivores

(See figure on next page.)

Fig. 3 Means for selected variables at each sample distance from the edge to define potential effects on richness and abundance of avian guilds at the Sakaerat Environmental Research Station in 2014-2015 based on generalized linear mixed models. Selected variables (y-axes) included: stem density of vegetation with heights between $0.5-3 \mathrm{~m}(\mathrm{D} 0)$, tree basal area (BA), maximum ambient noise (Noise), percentage cover of vegetation at $<0.5 \mathrm{~m}(\mathrm{C} 0), 3-5 \mathrm{~m}$ (C3), 5-10 $\mathrm{m}$ (C5) and $>10 \mathrm{~m}$ (C10) 

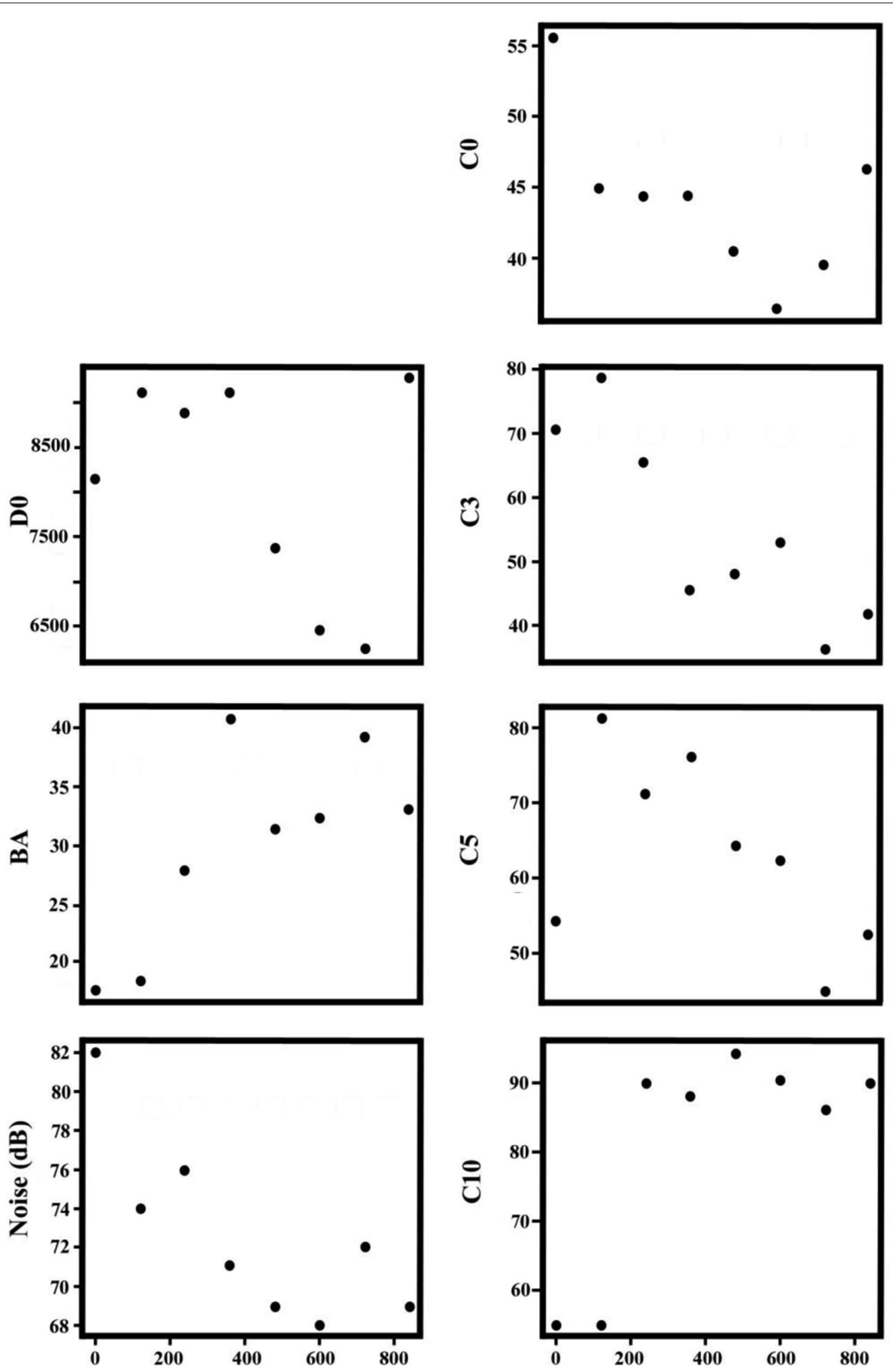

Distance from edge (m) 
Table 1 Candidate models $(\Delta \mathrm{AICc}<2)$ from generalized linear mixed models to explain the effects of forest edges on avian guilds at the Sakaerat Environmental Research Station in 2014-2015 based on variables included in the models

\begin{tabular}{|c|c|c|c|c|c|}
\hline Model $^{a}$ & $k$ & AICc & $\triangle \mathrm{AICC}$ & $w_{\mathrm{i}}$ & LL \\
\hline \multicolumn{6}{|l|}{ Richness } \\
\hline Edge* D0 & 7 & 4653.38 & 0.00 & 0.20 & -2319.67 \\
\hline Edge + D0 & 6 & 4653.77 & 0.39 & 0.17 & -2320.87 \\
\hline Edge ${ }^{*} \mathrm{CO}$ & 7 & 4654.60 & 1.22 & 0.11 & -2320.28 \\
\hline $\mathrm{Edge}+\mathrm{D} 0+\mathrm{C} 5+\mathrm{C} 0$ & 8 & 4654.70 & 1.32 & 0.10 & -2319.33 \\
\hline $\mathrm{Edge}+\mathrm{D} 0+\mathrm{CO}$ & 7 & 4654.75 & 1.37 & 0.10 & -2320.36 \\
\hline $\mathrm{Edge}^{*} \mathrm{D} 0+\mathrm{C} 5$ & 8 & 4655.31 & 1.93 & 0.08 & -2319.63 \\
\hline Edge & 3 & 4719.15 & 67.24 & 0.00 & -2327.84 \\
\hline D0 & 3 & 4728.79 & 76.87 & 0.00 & -2361.39 \\
\hline NULL & 2 & 7681.65 & 3029.74 & 0.00 & -3838.82 \\
\hline \multicolumn{6}{|l|}{ Abundance } \\
\hline Edge $*$ D0 & 7 & 5231.89 & 0.00 & 0.26 & -2608.93 \\
\hline $\mathrm{Edge}+\mathrm{D} 0+\mathrm{C} 5+\mathrm{C} 0$ & 8 & 5233.28 & 1.39 & 0.13 & -2608.61 \\
\hline $\mathrm{Edge}^{*} \mathrm{D} 0+\mathrm{CO}$ & 8 & 5233.70 & 1.81 & 0.11 & -2608.83 \\
\hline Edge & 3 & 5325.91 & 94.02 & 0.00 & -2659.95 \\
\hline D0 & 3 & 5330.18 & 98.29 & 0.00 & -2261.09 \\
\hline NULL & 2 & 9245.03 & 4013.14 & 0.00 & -4620.51 \\
\hline
\end{tabular}

Variables in our models included: distance to forest edge (Edge), stem density of vegetation with height between $0.5-3 \mathrm{~m}(\mathrm{D} 0)$, percentage cover of vegetation at $<0.5 \mathrm{~m}(\mathrm{C} 0)$ and 5-10 $\mathrm{m}$ (C5)

AICC Akaike's information criterion values, $\triangle A I C C$ the difference in AIC rank relative to the top model, $w_{i}$ the relative model weights, $k$ the number of parameters in the model, $L L$ log-likelihood

a Full set of models for richness and abundance modelled: Edge, Edge + D0, $\mathrm{Edge}+\mathrm{C0}, \mathrm{Edge}+\mathrm{D} 0+\mathrm{C0}, \mathrm{Edge}+\mathrm{D} 3, \mathrm{Edge}+\mathrm{D} 5, \mathrm{Edge}+\mathrm{DDBH}, \mathrm{Edge}+\mathrm{C} 05$, $\mathrm{Edge}+\mathrm{C} 5$, Edge $+\mathrm{D} 0+\mathrm{C} 5$, Edge $+\mathrm{D} 0+\mathrm{C} 5+\mathrm{C} 0$, Edge ${ }^{*} \mathrm{C} 3, \mathrm{Edge} * \mathrm{D} 3+\mathrm{D} 0$, Edge ${ }^{*} \mathrm{D} 0, \mathrm{Edge}^{*} \mathrm{D} 0+\mathrm{C} 5, \mathrm{Edge}{ }^{*} \mathrm{D} 0+\mathrm{C} 5+\mathrm{C} 0, \mathrm{Edge}^{*}{ }^{*} 5, \mathrm{Edge}^{*}{ }^{*} \mathrm{C}$, Edge ${ }^{*} \mathrm{DO}+\mathrm{CO}, \mathrm{Edge}^{*} \mathrm{DDBH}, \mathrm{Edge}{ }^{*} \mathrm{C} 5, \mathrm{Edge}{ }^{*} \mathrm{D} 5$. D3 is stem density of vegetation with height between $3-5 \mathrm{~m}, \mathrm{D} 5$ is stem density of vegetation with height between 5-10 m and DDBH is stem density of trees with $\mathrm{DBH}>5 \mathrm{~cm}$

(Table 3; Fig. 4a). We found only limited evidence to suggest there were negative effects of forest edge on the richness of foliage gleaning insectivores and raptors, although their richness were higher further from the edge (Table 3; Fig. 4a). We found no evidence to support effects of forest edge on the richness of granivore-insectivores, terrestrial insectivore-faunivores, and terrestrial insectivore-frugivores (Table 3).

Similar to richness, we found some evidence of negative effects of edge on the abundance of bark-gleaning, sallying, terrestrial, and understory insectivores (Table 3; Fig. 4b).

We also found some evidence suggesting positive effects of edges on abundance of arboreal nectarivoreinsectivores (Table 3; Fig. 4b). The abundances of barkgleaning, sallying, terrestrial, and understory insectivores were higher further away from the edge where the density of saplings, basal area, and percentage cover of vegetation in higher layers were higher, but percentage cover of vegetation in lower layers and ambient noise were lower (Fig. 3). There was very limited evidence to suggest there were negative edge effects on the abundance of arboreal frugivore-insectivores, foliage gleaning insectivores, and raptors, although their abundances were higher further from the edge (Table 3; Fig. 4b). We found no evidence to support edge effects on the abundance of granivoreinsectivores, terrestrial insectivore-faunivores, and terrestrial insectivore-frugivores (Table 3).

For most avian guilds, there were gradual shifts in abundance and richness from the edge into the interior; in contrast, the bark-gleaning insectivores were only observed at distances $>600 \mathrm{~m}$ from the edge (Fig. 4), which appeared to be related to basal area and vegetation cover at the canopy level (Fig. 3). The effect of traffic/ambient noise seemed to occur mostly within $100 \mathrm{~m}$ (Fig. 3) (see the results on the effect of traffic/ambient noise below). The vegetation structure near the forest edge $(<350 \mathrm{~m})$ was significantly different from the forest interior. The difference was most notable within $100 \mathrm{~m}$ from the edge (Fig. 3).

We generated 15 models to evaluate the influence of the potential variables on richness and abundance of avian guilds that were correlated with distance from edge. The models with strong support $(\triangle \mathrm{AICc}<2)$ included maximum ambient noise and largely the same variables (stem density of saplings, percentage cover of vegetation at $<0.5 \mathrm{~m}$ and $5-10 \mathrm{~m}$ ) as the models with strong support $(\triangle \mathrm{AICc}<2)$ from the analysis which included "distance from edge" without ambient noise. Maximum ambient noise was negatively associated with species richness $(\beta=-0.04)$ and abundance $(\beta=-0.06)$. Other variables in the top-ranked models and models with strong support that had influence on species richness included stem density of saplings $(\beta=0.22)$ and percentage cover at $5-10 \mathrm{~m}(\beta=-14)$. For abundance, stem density of saplings $(\beta=0.25)$, the interaction between maximum ambient noise and stem density of saplings $(\beta=-0.13)$, and percentage cover at $5-10 \mathrm{~m}(\beta=-12)$ were the important factors, with influence in the same direction as the models with distance from edge. Some bird guilds (sallying, terrestrial, and understory insectivores) responded negatively to ambient noise opposite to the responses to distance to edge; there was a strong negative correlation $(r=-0.8)$ between ambient noise and distance from edge.

\section{Discussion}

Loss and fragmentation of intact forest landscapes caused by roads and other infrastructure development leads to landscape transformation and loss of its conservation value (Potapov et al. 2017). We found support for 

Table 2 Estimates of coefficients of variables that suggest
significant influence on avian guild species richness
and abundance, standard errors (SE) and their 85\%
confidence intervals (CI) at the Sakaerat Environmental
Research Station in 2014-2015 derived from model
averaging

\begin{tabular}{lcccc}
\hline $\begin{array}{l}\text { Variables } \\
\text { estimated }\end{array}$ & Coefficient & SE & Lower 85\% Cl & Upper 85\% Cl \\
\hline Richness & & & & \\
Edge & 0.09 & 1.22 & -1.67 & 1.84 \\
D0 & $0.33^{\mathrm{a}}$ & 0.19 & 0.05 & 0.61 \\
Edge ${ }^{*}$ D0 & $-0.23^{\mathrm{a}}$ & 0.15 & -0.46 & -0.01 \\
C0 & -0.20 & 0.20 & -0.50 & 0.08 \\
Edge ${ }^{*}$ C0 & $0.35^{\mathrm{a}}$ & 0.09 & 0.21 & 0.49 \\
C5 & -0.18 & 0.22 & -0.50 & 0.13 \\
Abundance & & & & \\
Edge & 0.97 & 0.86 & -0.26 & 2.21 \\
D0 & $0.49^{\mathrm{a}}$ & 0.16 & 0.26 & 0.72 \\
Edge ${ }^{*}$ D0 & $-0.29^{\mathrm{a}}$ & 0.14 & -0.49 & -0.08 \\
C5 & $-0.32^{\mathrm{a}}$ & 0.19 & -0.59 & -0.05 \\
C0 & -0.25 & 0.25 & -0.62 & 0.11 \\
\hline
\end{tabular}

Edge represents distance to forest edge, D0 is stem density of vegetation with height between $0.5-3 \mathrm{~m}, \mathrm{C} 0$ is percentage cover of vegetation at $<0.5 \mathrm{~m}$, and C5 is percentage cover of vegetation at $5-10 \mathrm{~m}$

${ }^{a}$ Indicates estimated coefficients of variables that had a significant influence on avian guild richness and abundance

our hypothesis that edge effects influenced at least some avian guilds differently and that certain groups, including understory, sallying, terrestrial, and bark-gleaning insectivores, were observed to be higher in richness and abundance in the forest interior. Our study revealed complex spatial patterns in the bird community near a roadside forest edge at SERS in Thailand. Although most (69\%) species were found at all distances from the edge, in terms of avian guilds, proximity to the edge appeared to have negative effects on most avian guilds, but arboreal nectarivore-insectivores responded positively.

\section{Edge effects on avian guilds}

Overall, species richness and abundance of most avian guilds were reduced close to the edge, similar to findings of other tropical studies (Watson et al. 2004; Deikumah et al. 2014). Distance from the edge, density of saplings, basal area, and percentage cover of vegetation $>10 \mathrm{~m}$ had positive effects on most guilds. In contrast, increased vegetation cover in low and middle layers and ambient noise seemed to have negative effects. The vegetation structure near the forest edge was different from the forest interior. Differences extended to $350 \mathrm{~m}$ from the edge, but the clearest differences were within the first $100 \mathrm{~m}$. Similar to previous studies, forest edge areas had a higher density of small trees and saplings, resulting in higher vegetation cover near the ground but lower cover in the canopy, as well as lower total basal area and lower density of larger trees (Dale et al. 2000; Watson et al. 2004). However, the density of saplings in our study area was higher at both edge and deeper interior areas, but relatively lower at intermediate distances. Furthermore, the edge in our study was a busy (approximately 950 cars/h) five-lane highway with substantial traffic noise, especially within $100 \mathrm{~m}$ of the edge, which may have further negatively impacted at least some guilds as demonstrated elsewhere (Arevalo and Newhard 2011; Ware et al. 2015), and is further explained below.

\section{Influence of vegetation structure on avian community}

The lower richness and abundance of insectivores near the edge in our study was similar to other tropical studies (Laurance et al. 2004; Mammides et al. 2015), and may be explained by the relatively unsuitable microhabitats created by the increased understory density and reduced canopy cover, which may lead to higher light intensity, higher temperatures, and lower humidity (Pollock et al. 2015). Vegetation structure had the strongest effect on species richness and abundance of insectivorous birds, with higher complexity of vegetation structure positively associated with species richness and abundance of most insectivores, especially bark-gleaning, sallying, terrestrial, and understory insectivores (Ferger et al. 2014; Mammides et al. 2015). In our study area, vegetation structure within $100 \mathrm{~m}$ from the edge was generally simpler, with only one or two layers of particularly dense small trees and saplings and a greater cover of vegetation near ground level. These structural changes may have negatively affected the foraging microhabitats for understory insectivorous birds (Pollock et al. 2015). The reduced layers of small trees may limit shelter and foraging substrates for sallying and understory insectivores, such as the Black-naped Monarch (Hypothymis azurea) and Orange-breasted Trogon (Harpactes oreskios); whereas the greater cover at ground level may be an obstacle to terrestrial insectivores such as the Puff-throated Babbler (Pellorneum ruficeps). In contrast, the forest interior had a more complex vegetation structure, with a higher basal area, higher density of larger trees, more vegetation layers, and less ground cover, which probably provided more diverse arthropod resources and foraging habitats (Ferger et al. 2014).

Bark-gleaning woodpeckers and understory insectivores (trogons and kingfishers) also were negatively affected by the edge. Their richness and abundance were higher in the interior and positively related to the basal area, density of large trees and canopy cover, which has also been reported by Mahmoudi et al. (2016), and Whelan and Maina (2005). This group of birds may also 


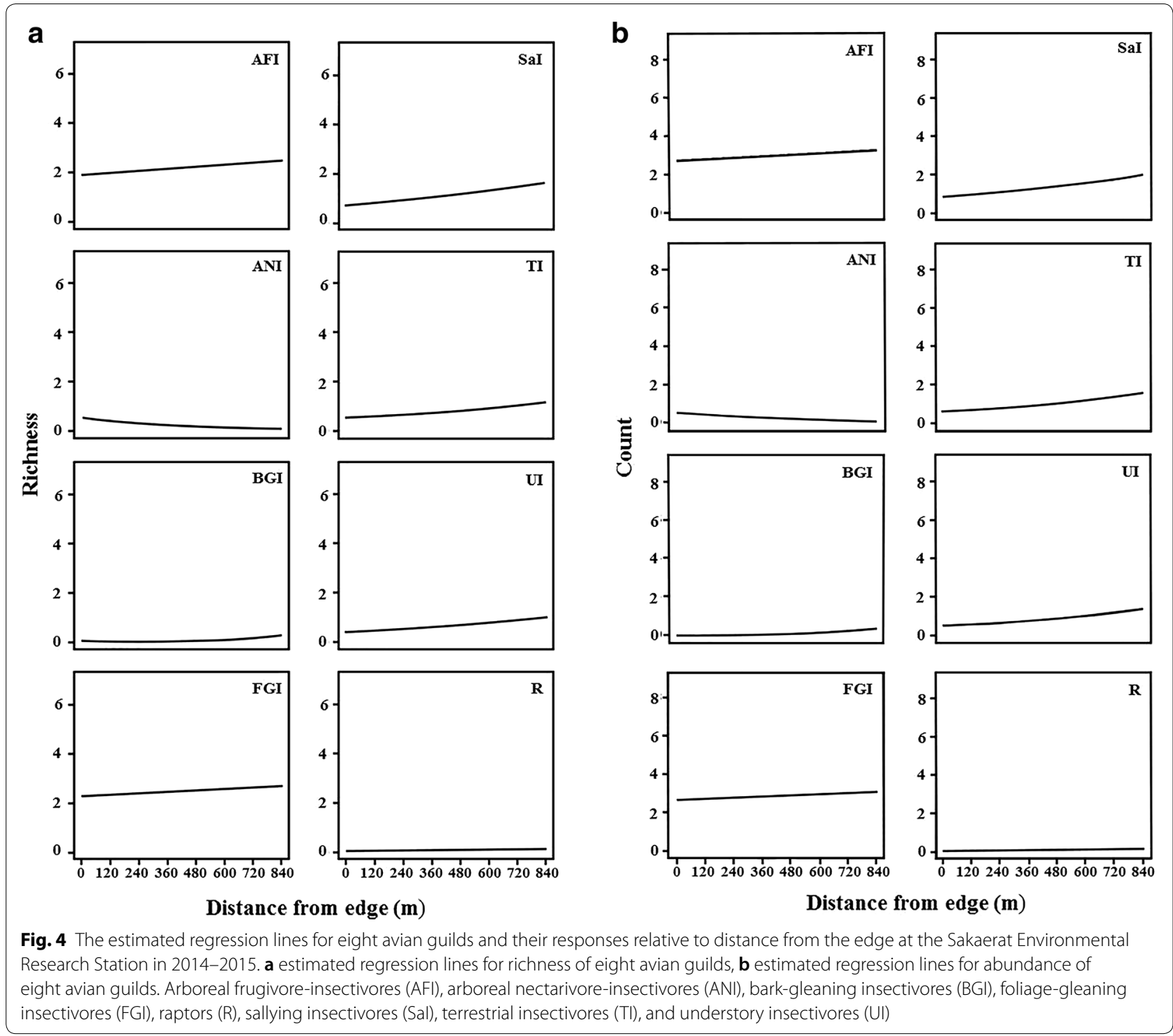

avoid edge areas due to the rarity of particular foraging and nesting substrates, including larger trees and stumps (Newton 1994; Lindell et al. 2004).

There was a small, but significantly negative response to edges by arboreal frugivore-insectivores, similar to some other studies in the tropics (Watson et al. 2004; Mammides et al. 2015). Slightly higher richness and abundance of frugivores in the forest interior may be associated with a higher basal area and density of large trees (Deikumah et al. 2014) and more potential food resources (Ferger et al. 2014). Higher basal area, density of large trees and vegetation cover at the canopy level of our forest interior could provide greater fruit availability (Lindenmayer et al. 2012). Some other studies have found frugivores to be tolerant to edges (Menke et al. 2012), but the tolerant species were mostly generalists, and included small-bodied frugivores such as the Yellow White-eye (Zosterops senegalensis) and Common Bulbul (Pycnonotus barbatus) that occur at soft edges with agriculture areas. On the other hand, richness and abundance of forest specialists and large-bodied frugivores, such as hornbills and pigeons, decreased at the edges (Deikumah et al. 2014; Mammides et al. 2015). Sixty percent of our birds in this guild were forest interior species (Round et al. 2011) and some had relatively larger body sizes, such as the Asian Fairy-bluebird (Irena puella; $70 \mathrm{~g}$ ), Oriental Pied Hornbill (Anthracoceros albirostris; $750 \mathrm{~g}$ ), and Thickbilled Green-pigeon (Treron curvirostra; 150 g). Moreover, the roadside habitat adjacent to our forest edge was unlikely to attract frugivores in the way that agricultural habitats often do. 
Table 3 Estimates of coefficients of 11 avian guilds for species richness and abundance response to edge effects, SE and their 95\% confidence intervals (CI) at the Sakaerat Environmental Research Station in 2014-2015

\begin{tabular}{|c|c|c|c|c|c|c|c|c|}
\hline \multirow[t]{2}{*}{ Guilds $^{\mathrm{a}}$} & \multicolumn{4}{|l|}{ Richness } & \multicolumn{4}{|l|}{ Abundance } \\
\hline & Coefficients & SE & Lower $95 \% \mathrm{Cl}$ & Upper $95 \% \mathrm{Cl}$ & Coefficients & SE & Lower $95 \% \mathrm{Cl}$ & Upper $95 \% \mathrm{Cl}$ \\
\hline AFI & 0.17 & 0.07 & 0.01 & 0.32 & 0.12 & 0.06 & -0.01 & 0.25 \\
\hline ANI & -1.25 & 0.28 & -1.81 & -0.68 & -1.38 & 0.28 & -1.94 & -0.81 \\
\hline BGl & 2.92 & 0.56 & 1.78 & 4.05 & 2.95 & 0.58 & 1.78 & 4.11 \\
\hline $\mathrm{FGl}$ & 0.11 & 0.07 & -0.03 & 0.25 & 0.10 & 0.06 & -0.03 & 0.23 \\
\hline Gl & -1.17 & 0.91 & -3.01 & 0.66 & -0.33 & 0.91 & -2.15 & 1.49 \\
\hline R & 0.83 & 0.45 & -0.08 & 1.74 & 0.81 & 0.44 & -0.07 & 1.69 \\
\hline Sal & 0.54 & 0.11 & 0.31 & 0.76 & 0.53 & 0.10 & 0.32 & 0.73 \\
\hline $\mathrm{Tl}$ & 0.51 & 0.13 & 0.24 & 0.77 & 0.64 & 0.11 & 0.40 & 0.87 \\
\hline TIF & 0.20 & 0.32 & -0.45 & 0.85 & 0.24 & 0.32 & -0.41 & 0.89 \\
\hline TIV & -1.16 & 0.68 & -2.53 & 0.21 & -0.66 & 0.61 & -1.88 & 0.56 \\
\hline UI & 0.62 & 0.14 & 0.32 & 0.91 & 0.68 & 0.13 & 0.41 & 0.94 \\
\hline
\end{tabular}

Positive coefficients indicate guilds that were more likely to be found away from the edge; negative coefficients indicate guilds that were more likely found near the edge

a Arboreal frugivore-insectivores (AFI), arboreal nectarivore-insectivores (ANI), bark-gleaning insectivores (BGI), foliage-gleaning insectivores (FGI), granivoreinsectivores $(\mathrm{Gl})$, raptors $(\mathrm{R})$, sallying insectivores (Sal), terrestrial insectivores (TI), terrestrial insectivore-frugivores (TIF), terrestrial insectivore-faunivores (TIV), and understory insectivores (UI)

The nectarivore-insectivore guild, such as sunbirds, was the only one to show a positive response to forest edge, similar to other studies (Laurance 2004; Watson et al. 2004). This guild depends greatly on nectar which is likely more abundant closer to the edge where higher light levels have been suggested to cause understory shrubs and lianas to produce more flowers, especially lianas which are also denser closer to the edge at all height levels (Levey 1988; Barber and Marquis 2011).

\section{Influence of traffic noise on avian community}

A decline in richness and abundance of birds close to road edges has been observed in many studies and noise may have significant effects on avian communities in general (Arevalo and Newhard 2011; Polak et al. 2013; Ware et al. 2015). Traffic noise from Route 304 was high (average $=67 \mathrm{~dB}$ ) within $100 \mathrm{~m}$ from the edge and then rapidly decreased into the interior. Noise disturbance from this busy five-lane highway could therefore be the primary explanation for the decline in richness and abundance for most avian guilds at the edge (Arevalo and Newhard 2011), although this effect was confounded with vegetation changes in our study. Traffic noise distracts birds, making them more vulnerable to predation, and disrupts the singing for pairing during the breeding season, which may have resulted in edge avoidance by some avian guilds (Arevalo and Newhard 2011; Polak et al. 2013), such as the terrestrial insectivores, Green-legged Partridge (Arborophila chloropus) and Puff-throated Babbler (Pellorneum ruficeps), that frequently vocally communicate especially during the breeding season. Because our assessment is correlative, we encourage future studies to further evaluate noise at edges in an experimental fashion to confirm this mechanism (e.g. Ware et al. 2015).

Finally, the lack of an edge effect on raptors may be explained by their wide-ranging behaviour, with movements likely larger than the distance we surveyed from the forest edge. We reported few raptors (0.02 individuals $/ \mathrm{km}^{2}$ ) and they typically occur at low densities (Andersen 2007). Minimal edge effects on foliage-gleaning insectivores may also be a result of life history traits of members in this guild, of which around half were small, non-forest specialists, including the Common Tailorbird (Orthotomus sutorius), Common Iora (Aegithina tiphia), and Plain Prinia (Prinia inornata) (Round et al. 2011). In the case of granivore-insectivores, terrestrial insectivore-faunivores, and terrestrial insectivore-frugivores, we found no evidence of edge effects on their richness and abundance. However, each of these guilds had only one species and their sample sizes were small.

\section{Conclusions}

The responses of avian guilds to edges can vary both between and within regions (Watson et al. 2004; Lindell et al. 2007), which creates a need for region-specific assessments. Thus, while it is difficult to extrapolate the effects of forest edges on avian communities from one relatively small study area and one type of edge to other forests, this is the first detailed study of the edge responses of birds in Southeast Asia, and the only study to investigate a roadside edge. Differences in vegetation structure and greater traffic noise made the forest edge 
less suitable for most avian guilds. However, traffic noise and vegetation structure are confounded in most analyses in our study, so we encourage future studies in which sound levels and canopy openness and/or understory vegetation density are experimentally varied.

Laurance et al. (2015) noted that "we are living in the most explosive era of infrastructure explosion in human history" and Southeast Asia is the epicentre for this expansion. Consistent with this observation, our study revealed impacts of a five-lane highway (Route 304), which runs adjacent to an intact forest landscape comprising three protected areas in Thailand, including our study area. Planners should avoid road development in forests of high conservation value to reduce impacts on biodiversity; such development also effects carbon storage, soil erosion and water catchments. Where avoidance is unavoidable, it may be possible to mitigate the impacts on forest bird communities by well-designed plantings of a dense buffer of fast-growing trees (Van Renterghem et al. 2012), restoration of vegetation (Arnold and Weeldenburg 1990), or use of earth berms along the roadside in sensitive areas. Natural barriers can reduce traffic noise as successfully as artificial noise barriers such as concrete walls, and natural noise barriers are likely to have less impact on the avian community in roadside habitats, although more detailed assessments of mitigation measures would likely be beneficial in this region. Trade-offs between development and conservation are unavoidable in many cases (Bennett 2017), so we encourage conservation planners to work with government agencies involved with road development and road maintenance projects to proactively minimize adverse impacts on avian communities in protected areas.

\section{Additional file}

Additional file 1. Table S1. List of bird species and their feeding guilds in the Sakaerat Environmental Research Station in 2014-2015.

\section{Authors' contributions}

DK, GAG, RTC, TS and AJL conceived and designed the study. DK performed the fieldwork. DK and GAG analyzed data and interpreted the results. DK wrote the original draft of this manuscript. GAG, LAP, RTC, TS and AJL reviewed and made comments to the manuscript. DK, GAG and LAP revised the final draft. All authors read and approved the final manuscript.

\section{Author details \\ ${ }^{1}$ Conservation Ecology Program, School of Bioresources and Technology, King Mongkut's University of Technology Thonburi, Bangkok, Thailand. ${ }^{2}$ Center for Integrative Conservation, Xishuangbanna Tropical Botanical Garden, Chinese Academy of Sciences, Yunnan, China. ${ }^{3}$ School of Natural Resources, University of Nebraska-Lincoln, Lincoln, NE, USA. ${ }^{4}$ Wild life Conservation Soci- ety, Global Conservation Program, New York, USA.}

\section{Acknowledgements}

We would like to thank T. Artchawakom, director of Sakaerat Environmental Research Station for permissions to conduct this study. Special thanks go to R.
Angkeaw for her full-time help in the field. We are also grateful to T. Klubchum, the Sakaerat bird team and the Conservation Ecology Program staff and students who provided support for this study. DK thanks S. Bumrungsri for advice on this project. We also thank D. Ngoprasert and W. Chutipong for their advice on the statistical analysis.

\section{Competing interests}

The authors declare that they have no competing interests.

\section{Consent for publication}

Not applicable.

\section{Ethics approval and consent to participate}

All procedures involving animals in this study complied with the current act regarding Animals for Scientific Purposes in Thailand and had the approval of the Animal Ethics Committee of King Mongkut's University of Technology Thonburi, Bangkok, Thailand. This study was permitted to do fieldwork in Sakaerat Environmental Research Station under the permission from the director of Sakaerat Environmental Research Station.

\section{Funding}

Our research was supported by King Mongkut's University of Technology Thonburi (Thailand) and the National Science and Technology Development Agency (CPMO P-14-51347). DK was supported by the Royal Golden Jubilee Ph.D. Program, Thailand (PHD/0036/2556).

Received: 25 October 2017 Accepted: 25 May 2018 Published online: 02 June 2018

\section{References}

Andersen DE. Survey techniques. In: Bird DM, Bildstein KM, editors. Raptor research and management techniques. Surrey: Hancock House Publishers; 2007. p. 89-100

Arevalo E, Newhard K. Traffic noise affects forest bird species in a protected tropical forest. Rev Biol Trop. 2011;59:969-80.

Arnold GW, Weeldenburg JR. Factors determining the number and species of birds in road verges in the wheatbelt of Western Australia. Biol Conserv. 1990;53:295-315.

Arnold TW. Uninformative parameters and model selection using Akaike's information criterion. J Wildl Manag. 2010;74:1175-8.

Barbaro L, van Halder I. Linking bird, carabid beetle and butterfly life-history traits to habitat fragmentation in mosaic landscapes. Ecography. 2009;32:321-33.

Barber NA, Marquis RJ. Light environment and the impacts of foliage quality on herbivorous insect attack and bird predation. Oecologia. 2011;166:401-9.

Barber CP, Cochrane MA, Souza CM Jr, Laurance WF. Roads, deforestation, and the mitigating effect of protected areas in the Amazon. Biol Conserv. 2014;177:203-9.

Bennett VJ. Effects of road density and pattern on the conservation of species and biodiversity. Curr Landsc Ecol Rep. 2017;2:1-11.

Bierregaard RO, Stouffer PC. Understory birds and dynamic habitat mosaics in Amazonian rainforests. In: Laurance WF, Bierregaard RO, editors. Tropical forest remnants: ecology, management, and conservation of fragmented communities. Chicago: University of Chicago Press; 1997. p. 138-55.

Bolker BA, Brooks ME, Clark CJ, Geange SW, Poulsen JR, Stevens MHH, White JS. GLMMs in action: gene-by-environment interaction in total fruit production of wild populations of Arabidopsis thaliana. Revised version, part 2. 2011. http://www.cell.com/cms/attachment/601623/4742453/mmc2. pdf. Accessed 2 Nov 2015

Dale S, Mork K, Solvang R, Plumptre AJ. Edge effects on the understory bird community in a logged forest in Uganda. Conserv Biol. 2000;14:265-76.

Dayananda SK, Goodale E, Lee MB, Liu JJ, Mammides C, Quan RC, Sreekar R, Yasuda M. Effects of forest fragmentation on nocturnal Asian birds: a case study from Xishuangbanna, China. Zool Res. 2016;37:151-8.

Deikumah JP, McAlpine CA, Maron M. Mining matrix effects on West African rainforest birds. Biol Conserv. 2014;169:334-43. 
Department of Highways. Annual Average Daily Traffic on Highways 2014, Bangkok. 2014. http://www.doh.go.th:88/dohnakhonratchasima/attac hments/article/30/report2557.pdf. Accessed 10 Oct 2016.

Ewers RM, Didham RK. Confounding factors in the detection of species responses to habitat fragmentation. Biol Rev Camb Philos Soc. 2006;81:117-42.

Ferger SW, Schleuning M, Hemp A, Howell KM, Böhning-Gaese K. Food resources and vegetation structure mediate climatic effects on species richness of birds. Glob Ecol Biogeogr. 2014:23:541-9.

Flaspohler DJ, Temple SA, Rosenfield RN. Species-specific edge effects on nest success and breeding bird density in a forested landscape. Ecol Appl. 2001;11:32-46.

Gale GA, Round PD, Pierce AJ, Nimnuan S, Pattanavibool A, Brockelman WY. A field test of distance sampling methods for a tropical forest bird community. Auk. 2009;126:439-48.

Gelman A, Hill J. Data analysis using regression and multilevel/hierarchical models. Cambridge: Cambridge University Press; 2007.

Haddad NM, Brudvig LA, Clobert J, Davies KF, Gonzalez A, Holt RD, Lovejoy TE, Sexton JO, Austin MP, Collins CD, Cook WM, Damschen El, Ewers RM, Foster BL, Jenkins CN, King AJ, Laurance WF, Levey DJ, Margules CR, Melbourne BA, Nicholls AO, Orrock JL, Song DX, Townshend JR. Habitat fragmentation and its lasting impact on Earth's ecosystems. Sci Adv. 2015. https://doi.org/10.1126/sciadv.1500052.

Halfwerk W, Holleman LM, Lessells CM, Slabbekoorn H. Negative impact of traffic noise on avian reproductive success. J Appl Ecol. 2011:48:210-9.

Jack J, Rytwinski T, Fahrig L, Francis CM. Influence of traffic mortality on forest bird abundance. Biodivers Conserv. 2015:24:1507-29.

Johns AD. Effect of selective logging on the ecology organization of a peninsular Malaysian rain forest avifauna. Forktail. 1986;1:65-79.

Lambert FR, Collar NJ. The future for Sundaic lowland forest birds: longterm effect of commercial logging and fragmentation. Forktail. 2002;18:127-46.

Laurance SGW. Responses to understory rain forest birds to road edges in central Amazonia. Ecol Appl. 2004;14:1344-57.

Laurance SG, Stouffer PC, Laurance WF. Effects of road clearings on movement patterns of understory rainforest birds in central Amazonia. Conserv Biol. 2004;18:1099-109.

Laurance WF, Peletier-Jellema A, Geenen B, Koster H, Verweij P, Van Dijck P, Lovejoy TE, Schleicher J, Van Kuijk M. Reducing the global environmental impacts of rapid infrastructure expansion. Curr Biol. 2015;25:259-62.

Lee TM, Soh MC, Sodhi N, Koh LP, Lim SLH. Effects of habitat disturbance on mixed species bird flocks in a tropical sub-montane rainforest. Biol Conserv. 2005;122:193-204

Levey DJ. Tropical wet forest treefall gaps and distributions of understory birds and plants. Ecology. 1988;69:1076-89.

Lindell CA, Chomentowski WH, Zook JR. Characteristics of bird species using forest and agricultural land covers in southern Costa Rica. Biodivers Conserv. 2004;13:2419-41.

Lindell CA, Riffell SK, Kaiser SA, Battin AL, Smith ML, SiskTD. Edge responses of tropical and temperate birds. Wilson J Ornithol. 2007;1 19:205-20.

Lindenmayer DB, Laurance WF, Franklin JF. Global decline in large old trees. Science. 2012;338:1305-6.

Mammides C, Schleuning M, Böhning-Gaese K, Schaab G, Farwig N, Kadis C, Coulson T. The indirect effects of habitat disturbance on the bird communities in a tropical African forest. Biodivers Conserv. 2015;24:3083-107.

Mahmoudi S, Ilanloo SS, Shahrestanaki AK, Valizadegan N, Yousefi M. Effect of human-induced forest edges on the understory bird community in Hyrcanian forests in Iran: implication for conservation and management. For Ecol Manag. 2016;382:120-8.

Menke S, Böhning-Gaese K, Schleuning M. Plant-frugivore networks are less specialized and more robust at forest-farmland edges than in the interior of a tropical forest. Oikos. 2012:121:1553-66.

Moradi HV, Zakaria M, Mohd A, Yusof E. Insectivorous birds and environmental factors across an edge-interior gradient in tropical rainforest of Malaysia. Int J Zool Res. 2009;5:27-41.
Murcia C. Edge effect in fragmented forest: implications for conservation. Trends Ecol Evol. 1995;10:58-62.

Newmark WD, Stanley TR. Habitat fragmentation reduces nest survival in an Afrotropical bird community in a biodiversity hotspot. Proc Natl Acad Sci USA. 2011;108:11488-93.

Newton I. The role of nest sites in limiting the number of hole-nesting birds: a review. Biol Conserv. 1994;70:265-76.

Polak M, Wiącek J, Kucharczyk M, Orzechowski R. The effect of road traffic on a breeding community of woodland birds. Eur J For Res. 2013;132:931-41.

Pollock HS, Cheviron ZA, Agin TJ, Brawn JD. Absence of microclimate selectivity in insectivorous birds of the Neotropical forest understory. Biol Conserv. 2015;188:116-25.

Potapov P, Hansen MC, Laestadius L, Turubanova S, Yaroshenko A, Thies C, Smith W, Zhuravleva I, Komarova A, Minnemeyer S, Esipova E. The last frontiers of wilderness: tracking loss of intact forest landscapes from 2000 to 2013. Sci Adv. 2017:3:e1600821.

Ralph CJ, Geupel GR, Pyle P, Martin TE, DeSante DF. Handbook of field methods for monitoring landbirds. Albany: U.S. Department for Agriculture; 1993.

Restrepo C, Gomez N. Responses of understory birds to anthropogenic edges in a neotropical montane forest. Ecol Appl. 1998:8:170-83.

Restrepo C, Gomez N, Heredia S. Anthropogenic edges, treefall gaps, and fruit-fruigivore interactions in a neotropical montane forest. Ecology. 1999;80:668-85.

Round PD, Pierce AJ, Sankamethawee W, Gale GA. The Avifauna of the Mo singto forest dynamics plot, Khao Yai national park, Thailand. Nat Hist Bull Siam Soc. 2011;57:57-80.

Sliwinski M, Powell P, Koper N, Giovanni M, Schacht W. Research design considerations to ensure detection of all species in an avian community. Methods Ecol Evol. 2016;7:456-62.

Sloan S, Sayer J. Forest Resources Assessment of 2015 shows positive global trends but forest loss and degradation persist in poor tropical countries. For Ecol Manag. 2015;352:134-45.

Stibig HJ, Achard F, Carboni S, Raši R, Miettinen J. Changes in tropical forest cover of Southeast Asia from 1990 to 2010. Biogeosciences. 2014;11:247-58.

Terraube J, Archaux F, Deconchat M, Halder I, Jactel H, Barbaro L. Forest edges have high conservation value for bird communities in mosaic landscapes. Ecol Evol. 2016:6:5178-89.

Van Renterghem T, Botteldooren D, Verheyen K. Road traffic noise shielding by vegetation belts of limited depth. J Sound Vib. 2012;331:2404-25.

Vetter D, Hansbauer MM, Végvári Z, Storch I. Predictors of forest fragmentation sensitivity in neotropical vertebrates: a quantitative review. Ecography. 2011;34:1-8.

Vetter D, Rücker G, Storch I. A meta-analysis of tropical forest edge effects on bird nest predation risk: edge effects in avian nest predation. Biol Conserv. 2013;159:382-95.

Ware HE, McClure CJW, Carlisle JD, Barber J. A phantom road experiment reveals traffic noise is an invisible source of habitat degradation. Proc Natl Acad Sci USA. 2015:112:12105-9.

Watson JEM, Whittaker RJ, Dawson TP. Habitat structure and proximity to forest edge affect the abundance and distribution of forest-dependent birds in tropical coastal forests of southern Madagascar. Biol Conserv. 2004:120:311-27.

Whelan CJ, Maina GG. Effects of season, understorey vegetation density, habitat edge and tree diameter on patch-use by bark-foraging birds. Funct Ecol. 2005;19:529-36

Wilcove DS, Giam X, Edwards DP, Fisher B, Koh LP. Navjot's nightmare revisited: logging, agriculture, and biodiversity in Southeast Asia. Trends Ecol Evol. 2013;28:531-40.

Wong TC, Sodhi NS, Turner IM. Artificial nest and seed predation experiments in tropical lowland rainforest remnants of Singapore. Biol Conserv. 1998:85:97-104. 